\title{
Pengaruh Strategi Pembelajaran Point Counter Point Terhadap Hasil Belajar
}

\author{
${ }^{1}$ Hadi Gunawan Sakti ( gunawansakti33@gmail.com ) \\ 2Endah Resnandari Puji Astuti (endahresnandaripujiastuti@gmail.com ) \\ 1,2Program Studi Teknologi Pendidikan, FIPP UNIVERSITAS PENDIDIKAN MANDALIKA.
}

\begin{abstract}
Abstrak
Permasalahan pada Hasil belajar siswa kelas XI MA Bayyinul Ulum Khususnya kelas XI.B pada mata pelajaran PKn masih terbilang rendah, itu terbukti dengan masih banyaknya peserta didik yang belum mencapai standar KKM, nilai tersebut merupakan hasil tes yang diberikan oleh guru kepada peserta didik. Hal tersebut terjadi dikarenakan masih banyaknya guru yang menggunakan metode konvensional dan kurang tepatnya dalam menggunakan strategi pembelajaran sehingga mengakibatkan menurunnya hasil belajar peserta didik. Oleh sebab itu, penelitian ini menggunakan strategi pembelajaran Point Counter Point, yaitu dimana dalam proses pembelajaran siswa dituntut dapat mengungkapkan ide/pendapatnya didepan siswa lainnya dan lebih aktif dan kritis dalam memecahkan permasalahan,sehingga dapat membantu meningkatkan hasil belajar siswa. Tujuan penelitian ini untuk mengetahui Pengaruh Strategi Pembelajaran Point Counter Point Terhadap Hasil Belajar Siswa Pada Mata Pelajaran PKN di MA Bayyinul Ulum Santong Kabupaten Lombok Utara Tahun Ajaran 2019/2020. Metode penelitian ini merupakan penelitian eksperimen, teknik pengambilan sampel yang digunakan secara acak sehingga pengambilan sampel ini di sebut random sampling. Teknik pengumpulan data dalam penelitian ini menggunakan metode tes sebagai metode pokok sedangkan dokumentasi sebagai metode pelengkap. Teknik analisis data menggunakan analisis statistik dengan rumus t-tes. Hasil analisis diperoleh nilai thitung sebesar 4,057 dan nilai $t_{\text {tabel }}$ pada taraf Signifikansi $5 \%$ dengan d.b $(\mathrm{N}-1)=26-1=$ 25 lebih besar dari pada nilai t pada tabel $(4,057>1,708)$, berarti bahwa Ho ditolak dan Ha diterima yang berbunyi: adanya Pengaruh Strategi Pembelajaran Point Counter Point terhadap Hasil belajar siswa Kelas XI pada mata pelajaran PKn di MA-Bayyinul Ulum Santong Kabupaten Lombok Utara Tahun Ajaran 2019/2020, sehingga dapat disimpulkan bahwa hasil penelitian ini "signifikan".
\end{abstract}

Kata Kunci: Strategi Pembelajaran Point Counter Point, Hasil Belajar.

\section{Abstract}

Problems with student outcomes in class XI MA Bayyinul Ulum Particularly in class XI.B in PKn subject was still relatively low, it was proven by the large number of students who have not yet reached the KKM standard, the value was the test results given by teachers to students. This happens because there are still many teachers who use conventional methods and are less precise in used learning strategies, the result in decreased students' outcomes of students. Therefore, this study used a Point Counter Point learning strategy, which where in the learning process students are required to be able to express their ideas / opinions in front of other students and be more active and critical in solving problems, so that they can help improve student learning outcomes. The purpose of this study was to determine The Effect of a Point Counter Point Learning Strategy to Increasing Students' outcomes Class XI in PKn Subject at MABayyinul Ulum Santong, North Lombok, in Academic Year 2019/2020. This research was an experimental, the sampling technique used sampling. Data collection techniques in this study used the test as the main method while documentation as a complementary method. Data analysis techniques used statistical analysis with the t-test formula. The analysis results obtained t-test of 4.057 and the value of the t-table at the Significance level of $5 \%$ with $\mathrm{db}(\mathrm{N}-1)=26-1=25$ was greater than the value of t-able $(4.057>1.708)$, it means that H0 was rejected and Ha was accepted which: There was The Effect of a Point Counter Point Learning Strategy to Increasing Students' outcomes Class XI in PKn Subject at MABayyinul Ulum Santong, North Lombok, in Academic Year 2019/2020., so it can be concluded that the results of this study was "significant".

Keywords: Point Counter Point Learning Strategy, Students' Outcomes. 


\section{PENDAHULUAN}

Pendidikan berasal dari kata "didik", lalu kata ini mendapat awalan "me" sehingga menjadi "mendidik" artinya, memelihara dan memberi latihan. Dalam memelihara dan memberi latihan diperlukan adanya ajaran, tuntunan, dan pimpinan mengenai akhlak dan kecerdasan pikira (Muhibbin Syah, 2010:10). Sekolah juga merupakan salah satu tempat para siswa untuk berinteraksi dan memperoleh pengalaman baru. Menurut Undang-Undang No.20 tahun 2003 tentang Sistem Pendidikan Nasional Bab 1 Pasal 1 (ayat 1) dijelaskan bahwa pendidikan adalah usaha sadar dan terencana untuk mewujudkan suasana belajar dan proses pembelajaran agar peserta didik secara aktif mengembangkan potensi dirinya untuk memiliki kekuatan spiritual keagamaan, pengendalian diri, kepribadian, kecerdasan, akhlak mulia, serta keterampilan yang diperlukan dirinya, masyarakat, bangsa, dan negara. Dalam proses pendidikan pendidik memegang peran yang sangat penting dalam proses belajar mengajar. Dipundaknya terpikul tanggung jawab utama keefektifan seluruh usaha kependidikan di sekolah. Dalam keseluruhan proses pendidikan di sekolah interaksi belajar mengajar mempunyai suatu arti adanya interaksi dari suatu pengajar secara optimal demi membimbing dan mengarahkan belajar siswa agar dapat mencapai tujuan pendidikan.

Begitu pentingnya pendidikan sehingga harus dijadikan prioritas utama dalam pembangunan bangsa. Pentingnya pendidikan tersebut menyebabkan perlu adanya peningkatan mutu dalam pendidikan yang dilakukan secara menyeluruh, mencakup semua aspek pendidikan. Pembaharuan sangat diperlukan dalam proses pendidikan, mutu pendidikan, perangkat kurikulum, sarana dan prasarana pendidikan dan mutu menejemen pendidikan termasuk perubahan dalam strategi pembelajaran yang lebih inovatif. Rendahnya hasil belajar peserta didik jugadapat disebabkan oleh tidak adanya Strategi dalam proses pembelajaran tersebut membuat siswa menjadi kurang aktif dalam proses pembelajaran, dan timbul kurangnya pemahaman peserta didik pada materi yang dipelajari. Upaya perubahan dan perbaikan tersebut bertujuan membawa kualitas pendidikan supayaa menjadi lebih baik.

Strategi berasal dari Bahasa Yunani yaitu strategos yang berarti jendral atau panglima, sehingga strategi diartikan sebagai ilmu kejendralan atau ilmu kepanglimaan. Strategi dalam pengertian kemiliteran ini berarti cara penggunaan seluruh kekuatan militer untuk mencapai tujuan perang. Dalam perkembangan selanjutnya strategi diterapkan dalam dunia pendidikan terutama dalam pembelajaran. Menurut Gerlach dan Ely (Hamdani, 2011:19) menjelaskan bahwa "Strategi pembelajaran merupakan cara yang di pilih untuk menyampaikan materi pembelajaran dalam lingkungan pengajaran tertentu yang meliputi sifat, lingkup dan urutan kegiatan yang dapat memberikan pengalaman belajar kepada siswa.

Banyaknya strategi pembelajaran ataupun model pembelajaran di dunia Pendidikan. Namun jarang diaplikasikan dalam proses pembelajaran banyaknya strategi pembelajaran ataupun model pembelajaran hanya sebagai pengetahuan saja oleh pendidik. Salah satu strategi pembelajaran adalah strategi pembelajaran Point Counter point. Strategi pembelajaran Point Counter point biasa dikatakan jarang digunakan disekolah. Padahal penggunaan strategi ini mampu dan yakin biasa meninkatkan hasil belajar siswa dan siswa akan memperoleh hasil yang maksimal dan efektif dalam proses pembelajaran.strategi pembelajaran Point Counter point adalah suatu cara dalam proses pembelajaran yang memberikan kesempatan kepada siswa untuk aktif berargumen (mengajukan ide-ide, gagasan-gagasan) dari persoalan-persoalan yang muncul atau sengaja dimunculkan dalam pembelajaran sesuai dengan aturan-aturan yang telah ada (Dewi Wulandari, 2012 : 163). Menurut teori Gerlach dan Elly (dalam Isnu Hidayat, 2019:32) menjelaskan bahwa strategi pembelajaran merupakan cara-cara yang dipilih untuk menyampaikan materi pembelajaran dalam lingkungan tertentu.

Berdasarkan survey lapangan di sekolah MA-Bayyinul Ulum Santong Kabupaten Lombok Utara khususnya Kelas Xl ditemukan bahwa strategi pembelajaran yang di terapkan oleh tenaga pendidik masih Tradisional dalam plaksanaan pembelajaran. Paling banyak ditemui adalah model ceramah pada saat pembelajaran berlangsung akibatnya siswa kurang aktif dalam mengikuti proses pembelajaran dan tidak di berikan kebebasan untuk mengutarakan pendapat dalam proses pembelajaran di dalam kelas hal tersebut terlihat ketika proses pembelajaran berlangsung. Sehingga menyebabkan hasil belajar siswa pada mata pelajaran Pendidikan Kewargaan Negara (PKn) terlihat kurang/hasilnya tidak sesuai yang di harapkan oleh pendidik.

Berdasarkan pemikiran diatas, agar peserta didik memperoleh peningkatan pada hasil belajar dan pembelajaran menyenangkan serta bermakna untukpeserta didik. Hal ini menjadi pertimbangan utama bagi peneliti sehingga terdorong untuk mengadakan penelitian dengan judul:"Pengaruh Strategi PembelajaranPoint Counter Point terhadap Hasil belajar 
siswa Kelas XI pada mata pelajaran PKn di MA-Bayyinul Ulum Santong Kabupaten Lombok Utara".

\section{METODE PENELITIAN}

Rancangan penelitian ini diartikan sebagai strategi mengatur latar (setting) agar penelitian memperoleh data yang valid sesuai dengan tujuan dalam penelitian. Pendekatan yang digunakan dalam penelitian ini adalah penelitian kuantitatif jenis eksperimen, penelitian kuantitatif adalah suatu proses menemukan pengetahuan yang menggunakan data berupa angka sebagai alat menganalisis keterangan mengenai apa yang ingin diketahui (Margono, 2014: 105).

Peneliti menggunakan satu kelas yaitu kelas eksperiment. Kelas eksperiment adalah kelas yang disengaja untuk di beri seperangkat perlakuan Pembuatan rancangan penelitian sendiri bertujuan agar penelitian bisa dijalankan dengan lancar. Dalam penelitian ini menggunakan one group pretest posttest design. Dengan cara ini hasil perlakuan dapat di ketahui lebih akurat karna dapat membandingkan dengan keadaan sebelum diberi perlakuan. Designe ini dapat di gambarkan sebagai berikut:

\section{$01 \times 02$ \\ Ket: $\quad$ O1=Nilai pretest $\mathrm{O} 2=$ Nilai posttest}

(Sugiyono:2015:111)

Populasi adalah wilayah generalisasi yang terdiri atas: obyek/subyek yang mempunyai kualitas dan karateristik tertentu yang ditetapkan oleh peneliti untuk dipelajari dan kemudian ditarik kesimpulannya. (Sugiyono,2013:61). Populasi adalah seluruh data yang menjadi perhatian kita dalam suatu ruang lingkup dan waktu yang kita tentukan. (Margono,2014:118)

Dari pendapat para ahli di atas bahwa populasi adalah keseluruhan dari obyek penelitian. Dalam penelitian ini yang menjadi populasi adalah seluruh siswa kelas XI di MABayyinul Ulum Santong Kabupaten Lombok Utara dengan jumbelah keseluruhan yaitu sebanyak 66 siswa yang terdiri dari 3 kelas.

Sampel adalah sebagai bagian dari populasi, sebagai contoh (monster) yang diambil dengan menggunakan cara-cara tertentu. (Margono, 2014:121). Sampel adalah bagian dari jumlah dan karakteristik yang di miliki oleh populasi. Bila populasi besar, dan peneliti tidak mungkin mempelajari semua yang ada pada populasi. Apa yang dipelajari dari sampel, kesimpulannya akan dapat diberlakukan untuk populasi. Untuk itu sampel yang di ambil dari populasi harus betul-betul representatif (mewakili). Sugiyono (2013:62). Dalam penelitian ini tidak menarik sampling karena populasi yang relative sedikit sehingga penelitian ini dinamakan studi populasi,

Adapun Untuk menentukan sampel yang akan digunakan secara acak sehingga pengambilan sampel ini di sebut random sampling. Setelah melakukan random sampling terhadap populasi jumbelah sampel dalam penelitian saya ini yaitu siswa kelas XI.B dengan jumbelah siswa perempuan yaitu sebanyak 16 orang siswa dan jumbelah siswa laki-laki yaitu 10 orang siswa jadi jumbelah total siswa sebanyak 26 siswa.

Instrumen sebagai alat pengumpul data harus betul-betul dirancang dan dibuat sedemikian rupa sehingga menghasilkan data empiris sebagai mana adanya. Data yang salah atau tidak menggambarkan data empiris bisa menyesatkan peneliti, sehingga kesimpulan penelitian yang ditarik/dibuat peneliti bisa keliru. Margono (2014:155).

Untuk mengetahui data tentang hasil belajar terhadap Hasil belajar siswa Kelas XI di MA-Bayyinul Ulum Santong Kabupaten Lombok Utara Tahun Pelajaran 2019/2020 berbentuk tes yang dibuat oleh guru,bertujuan untuk mengetahui hasil belajar siswa. Adapun instrument dalam peneliltian ini menggunakan tes pilihan ganda jumlah item soal 20 dengan 4 alternatif jawaban. Untuk jawaban benar diberi nilai 1. sedangkan untuk jawaban salah diberi nilai 0 .

Adapun metode analisis data yang digunakan dalam penelitian ini adalah analisis data statistic dengan rumus $t$-test sebagai berikut: 
Keterangan :

$$
t=\frac{M d}{\sqrt{\frac{\sum x d^{2}}{N(N-1)}}}
$$

Md : Mean dari perbedaan pre tes dengan pos tes (pos test-pre test)

$\mathrm{Xd} \quad$ : Deviasi masing-masing subyek (d-Md)

$\sum x d^{2}$ : Jumlah Kuadrat deviasi

$N \quad$ : Jumlah Subyek pada sampel

$d b \quad$ : ditentukan dengan $\mathrm{N}-1$

$$
N-\text { Gain }=\frac{\text { Posttest Score }- \text { Pretest Score }}{\text { Maksimum Score }- \text { Pretest Sc/re }}
$$

Ket : N-Gain $=$ Gain yang ternomalisir

Pretest $=$ Nilai awal pembelajaran Posttest $=$ Nilai akhir Pembelajaran

Adapun Langkah-langkah yang akan ditempuh selanjutnya dalam menganalisa data penelitian ini adalah :

1. Merumuskan hipotesis nol (Ho)

2. Membuat tabel kerja

3. Memasukan tabel kedalam rumus

4. Menguji nilai $t$-tes

5. Menarik kesimpulan analisis

Kreteria penolakan $\mathrm{H} 0$ dan penerimaan Ha dapat dijelaskan sebagai berikut : jika $t$ hitung lebih besar dari $t$ tabel maka Ha diterima dan HO ditolak, sedangkan apabila $t$ hitung lebih keci ldari $t$ tabel maka Ha ditolak dan $\mathrm{H} 0$ diterima.

\section{HASIL PENELITIAN}

1. Merumuskan Hipotesis

Untuk kepentingan perhitungan analisis statistik, maka hipotesis alternatif $\left(H_{a}\right)$ yang berbunyi: adapun pengaruh strategi pembelajaran Point Counter Point terhadap hasil belajar siswa kelas XI Mata Pelajaran PKn di MA-Bayyinul Ulum Santong Kabupaten Lombok Utara Tahun ajaran 2019/2020.

2. tabel kerja untuk menguji hipotesis tentang pengaruh strategi Pembelajaran Point Counter Point terhadap hasil belajar siswa kelas XI Mata Pelajaran PKn di MA-Bayyinul Ulum Santong.

Ulum Santong.

\begin{tabular}{|c|c|c|c|c|c|c|}
\hline No & $\begin{array}{c}\text { Kod } \\
\mathbf{e} \\
\text { Sub } \\
\text { yek }\end{array}$ & $\begin{array}{c}\text { Pr } \\
\text { e- } \\
\text { tes } \\
\text { t }\end{array}$ & $\begin{array}{c}\text { Pos } \\
\text { t- } \\
\text { test }\end{array}$ & $\begin{array}{c}\text { Ga } \\
\text { in } \\
\text { (d) }\end{array}$ & $\begin{array}{c}\text { Xd } \\
\text { (d- } \\
\text { Md) }\end{array}$ & $\sum \boldsymbol{X}$ \\
\hline 1 & FH & 8 & 10 & & & 0. \\
\hline 2 & MA & 10 & 12 & 2 & -0.8 & $\begin{array}{c} \\
64\end{array}$ \\
\hline 3 & FA & 11 & 13 & & & 0. \\
& & & & 2 & -0.8 & 64 \\
\hline 4 & JM & 9 & 10 & & & 3. \\
& & & & 1 & -1.8 & 24 \\
\hline 5 & RS & 13 & 11 & & & 23 \\
& & & & & & -0 \\
& & & & -2 & -4.8 & 4 \\
\hline
\end{tabular}




\begin{tabular}{|c|c|c|c|c|c|c|}
\hline 6 & NN & 11 & 11 & 0 & -2.8 & $\begin{array}{l}7 . \\
84\end{array}$ \\
\hline 7 & $\mathrm{EF}$ & 13 & 14 & 1 & -1.8 & $\begin{array}{l}3 . \\
24 \\
\end{array}$ \\
\hline 8 & $\mathrm{SC}$ & 6 & 6 & 0 & -2.8 & $\begin{array}{r}7 . \\
84 \\
\end{array}$ \\
\hline 9 & UN & 6 & 16 & 10 & 7.2 & $\begin{array}{r}51 \\
.8 \\
4 \\
\end{array}$ \\
\hline 10 & RL & 7 & 8 & 1 & -1.8 & $\begin{array}{l}3 . \\
24\end{array}$ \\
\hline 11 & $\mathrm{KN}$ & 13 & 15 & 2 & -0.8 & $\begin{array}{l}0 . \\
64\end{array}$ \\
\hline 12 & NA & 8 & 8 & 0 & -2.8 & $\begin{array}{l}7 . \\
84\end{array}$ \\
\hline 13 & $\mathrm{RS}$ & 13 & 16 & 3 & 0.2 & $\begin{array}{l}0 . \\
04\end{array}$ \\
\hline 14 & $\mathrm{AR}$ & 11 & 13 & 2 & -0.8 & $\begin{array}{l}0 . \\
64\end{array}$ \\
\hline 15 & $\mathrm{DG}$ & 11 & 7 & -4 & -6.8 & $\begin{array}{c}46 \\
.2 \\
4\end{array}$ \\
\hline 16 & DS & 6 & 9 & 3 & 0.2 & $\begin{array}{l}0 . \\
04\end{array}$ \\
\hline 17 & LA & 5 & 10 & 5 & 2.2 & $\begin{array}{l}4 . \\
84\end{array}$ \\
\hline 18 & $\mathrm{AS}$ & 5 & 8 & 3 & 0.2 & $\begin{array}{l}0 . \\
04\end{array}$ \\
\hline 19 & $\mathrm{AF}$ & 7 & 8 & 1 & -1.8 & $\begin{array}{l}3 . \\
24 \\
\end{array}$ \\
\hline 20 & $\mathrm{ARH}$ & 6 & 11 & 5 & 2.2 & $\begin{array}{l}4 . \\
84 \\
\end{array}$ \\
\hline 21 & RAK & 6 & 16 & 10 & 7.2 & $\begin{array}{c}51 \\
.8 \\
4\end{array}$ \\
\hline 22 & $\mathrm{SF}$ & 7 & 18 & 11 & 8.2 & $\begin{array}{r}67 \\
.2 \\
4\end{array}$ \\
\hline 23 & MS & 12 & 12 & 0 & -2.8 & $\begin{array}{l}7 . \\
84\end{array}$ \\
\hline 24 & $\mathrm{MH}$ & 8 & 12 & 4 & 1.2 & $\begin{array}{l}1 . \\
44\end{array}$ \\
\hline 25 & $\mathrm{RH}$ & 11 & 18 & 7 & 4.2 & $\begin{array}{r}17 \\
.6 \\
4\end{array}$ \\
\hline 26 & MM & 15 & 19 & 4 & 1.2 & $\begin{array}{l}1 . \\
44\end{array}$ \\
\hline \multicolumn{2}{|c|}{ Jumlah } & $\begin{array}{c}23 \\
8\end{array}$ & 311 & 73 & & 31 \\
\hline & $\begin{array}{l}\text { lai } \\
\text {-rata }\end{array}$ & $\begin{array}{c}9.1 \\
5\end{array}$ & $\begin{array}{c}11.9 \\
6\end{array}$ & 2.8 & & $\begin{array}{l}8 . \\
04\end{array}$ \\
\hline
\end{tabular}

Sumber: (MA Bayyinul Ulum Santong)

3. Memasukkan data ke Dalam Rumus

Berdasarkan data pada tabel kerja, diketahui nilai-nilai yang didapatkan adalah sebagai berikut:

$$
\Sigma \mathrm{X}_{1}=238 \quad \mathrm{Md}=\frac{73}{26}=2.8
$$



$\Sigma \mathrm{X}_{2}=311$
$\Sigma \mathrm{x}^{2} \mathrm{~d}=318.04$
$\Sigma \mathrm{d}=73$
$\mathrm{N}(\mathrm{N}-1)=26(26-1)=650$

Setelah mengetahui nilai di atas, maka nilai tersebut dimasukkan ke dalam rumus $t$-test sebagai berikut:

$$
\begin{aligned}
& t=\frac{M d}{\sqrt{\frac{\sum x^{2} d}{N(N-1)}}} \\
& t=\frac{2.8}{\sqrt{\frac{318.04}{26(26-1)}}} \\
& t=\frac{2.8}{\sqrt{\frac{318.04}{650}}} \\
& t=\frac{2.8}{\sqrt{0,48}} \\
& t=\frac{2.8}{0,69} \\
& t=4.057
\end{aligned}
$$

\section{PEMBAHASAN}

Sesuai dengan perhitungan $t$-test nilai yang diperoleh adalah 4.057 sedangkan nilai $t$ test dalam table dengan 4.057 sedangkan nilai $t$-test dalam tabel dengan db $(\mathrm{N}-1)=26-1=25$ pada taraf signifikasi $10 \%(0,10)$ adalah $=1.708$ dengan demikian bahwa nilai $t$-test analisis lebih besar daripada nilai t-tabel (4.057>1.708). Hal ini berarti hipotesis nihil ( $\left.\mathrm{H}_{0}\right)$ yang diuji ditolak dan hipotesis alternatif (Ha) yang diajukan yang diterima.

Dari hasil ujian $t$-test menunjukan nilai t-hitung sebesar 4,057 maka berdasarkan taraf signifikasi $10 \%$ dan $\mathrm{db}=26-1=25$ ternyata besar angka batas penolakan hipotesis nihil $\left(\mathrm{H}_{0}\right)$ yang dinyatakan dalam tabel distribusi t adalah 1.708 . pernyataan ini menunjukkan bahwa $t$ hitung lebih besar dibandingkan $t$-tabel $(4.057>1.708)$ karena $t$-hitung lebih besar dibandingkan $t$ tabel, maka penelitian ini dikatakan signifikan. Hal ini berarti bahwa hipotesis nihil $\left(\mathrm{H}_{0}\right)$ di tolak dan hipotesis alternatif (Ha) diterima, maka dapat ditarik kesimpulan bahwa: Terdapat Pengaruh Strategi Pembelajaran Point Counter Point Terhadap Hasil Belajar Siswa Kelas XI Pada Mata Pelajaran PKn Di MA Bayyinul Ulum Santong Kabupaten Lombok Utara Tahun Ajaran 2019/2020.

\section{KESIMPULAN}

. Berdasarkan rumusan masalah penelitian yang ada pada bab I, maka peneliti melakukan penelitian ini untuk mengetahui apakah ada Pengaruh Strategi Pembelajaran Point Counter Point Terhadap Hasil Belajar Siswa Kelas XI Pada Mata Pelajaran PKn Di MA Bayyinul Ulum Santong Kabupaten Lombok Utara Tahun Ajaran 2019/2020. Penelitian ini dilakukan dengan menggunakan rancangan penelitian one group pre-test - post-test design. Pada awal pertemuan, Hari Jum'at,14 Februari 2020 siswa diberikan pre-test untuk mengetahui sejauh mana pemahaman siswa mengenai materi yang akan diajarkan. Pertemuan selanjutnya, hari Jum'at,21 Februari 2020 dilakukan suatu perlakuan dengan memberikan materi menggunakan strategi pembelajaran Point Counter Point Pembelajaran selama tiga jam pelajaran. Setelah perlakuan dilakukan, pertemuan selanjutnya, hari Jum'at,28 Februari 2020 siswa diberikan post-test untuk mengetahui sejauh mana siswa menguasai materi yang sudah diajarkan dengan strategi pembelajaran Point Counter Point, dan untuk mengetahui seberapa efektif strategi pembelajaran Point Counter Point media terhadap hasil belajar siswa Kelas XI Pada Mata Pelajaran PKn di MA Bayyinul Ulum Santong. Selain itu, peneliti juga menggunakan metode dokumentasi untuk mendukung hasil penelitian.

Berdasarkan hasil analisis data dimana t-hitung $>$ t-tabel yaitu 4.057 $>1.708$ dengan taraf signifikan $10 \%$ dengan $\mathrm{N}=26$ sesuai dengan analisis data yang telah diperoleh melalui penelitian dengan menggunakan rumus $t$-test, ternyata hipotesis nihil (Ha) diterima, maka dari itu dapat ditarik kesimpulan bahwa "Terdapat Pengaruh Strategi Pembelajaran Point 
Counter Point Terhadap Hasil Belajar siswa Kelas XI Pada Mata Pelajaran PKn Di MA Bayyinul Ulum Santong Kabupaten Lombok Utara Tahun Ajaran 2019/2020.

Pada penelitian yang relevan pada bab sebelumnya telah ditemukan adanya kelebihan menggunakan strategi pembelajaran Point Counter Point yaitu proses pembelajaran lebih aktif dan memudahkan guru untuk mengetahui hasil belajar siswa serta strategi ini juga memberikan siswa lebih aktif karena strategi ini juga mirip seperti strategiu pembelajaran Debate yang mengharuskan siswa berperan lebih aktif ketika proses pembelajaran berlangsung.

Strategi pembelajaran Point Counter point merupakan strategi yang mengasah argumen, ide-ide dan gagasan-gagasan siswa untuk menyelesaikan permasalahan yang menimbulkan perbedaan pandangan/pemikiran dengan cara mendiskusikannya dengan teman-teman yang lain. Kelebihan dan Kekurangan Strategi PembelajaranPoint Counter Point yaitu (a) Dengan diskusi akan mempertajam hasil pembicaraan. (b) Siswa dapat terangsang untuk menganalisa masalah di dalam kelompok, asal terpimpin sehingga analisa itu terarah pada pokok permasalahan yang dikehendaki bersama. (c) Dalam pertemuan debat itu siswadapat menyampaikan fakta dari kedua sisi masalah; kemudian di teliti fakta mana yang benar/valid dan bisa di pertanggung jawabkan bersama dalam satu kelompok. (d) Karena terjadi pembicaraan aktif antar kelompok maka akan membangkitkan daya tarik para siswauntuk turut berbicara, turut berpartisipasi untuk mengeluarkan pendapat. (e) apabila permasalahan yang didiskusikan menarik, maka pembicaraan itu mampu mempertahankan minat anak untuk terus mengikuti pendapat itu. (f) strategi ini dapat di gunakan pada kelompok yang besar.

Penentuan suatu strategi pembelajaran yang akan digunakan sangat penting, karena strategi pembelajaran akan ikut menentukan keberhasilan proses pembelajaran. Apabila strategi pembelajaran yang digunakan tepat, maka akan berpengaruh terhadap hasil belajar siswa. Sangat penting bagi seorang guru untuk mengetahui atau mempertimbangkan strategi pembelajaran yang akan digunakan untuk meningkatkan hasil belajar siswa dan membantu dalam pencapaian tujuan pembelajaran. Karena penggunaan suatu strategi pembelajaran akan dikatakan berhasil atau efektif apabila dapat meningkatkan hasil belajar siswa serta dapat mencapai tujuan pembelajaran.

Dengan demikian pengaruh strategi pembelajaran Point Counter Point Terhadap Hasil belajar siswa sangat penting dan yang dapat diharapkan dapat merangsang minat belajar siswa, memberikan kesempatan agar siswa lebih aktif serta rajin dalam proses pembelajaran, dan guru hanya memberikan bantuan secara bertahap sehingga merangsang siswa untuk bagaimana aktif dalam mengutarakan apa yang menjadi pendapat siswa tentang materi yang di bahas agar dapat mengembangkan keaktifan siswa di dalam proses pembelajaran agar hasil belajar siswa lebih baik dan meninggkat seperti yang diinginkan oleh seorang didik.

\section{DAFTAR PUSTAKA}

Dewi Wulandari, 2012. Pengaruh Strategi Pembelajaran Point Counter point.VOL. 01 NO. 03, edisi Nopember 2012 .

Hamdani, 2011. Strategi Belajar Mengajar. Bandung : Pustaka Setia.

Hidayat, Isnu.2019. 50 Strategi Pembelajaran Populer. Yogjakarta: DIVA Press.

Muhibbin, Syah 2010, Psikologi Pendidikan Dengan Pendidikan Baru.Bandung PT Remaja Rosdakarya.

Margono, S. 2014. Metode Penelitian Pendidikan. Jakarta: Rineka Cipta.

.2014. Metode Penelitian Pendidikan. Jakarta: Rineka Cipta.

.2014. Metode Penelitian Pendidikan. Jakarta: Rineka Cipta.

Sugiyono.2012. metode penelitian kuantitatif kualitatif dan R\&D. Bandung:Alfabeta. 
2012. metode penelitian kuantitatif kualitatif dan $R \& D$. Bandung:Alfabeta. .2012. metode penelitian kuantitatif kualitatif dan $R \& D$. Bandung:Alfabeta. 